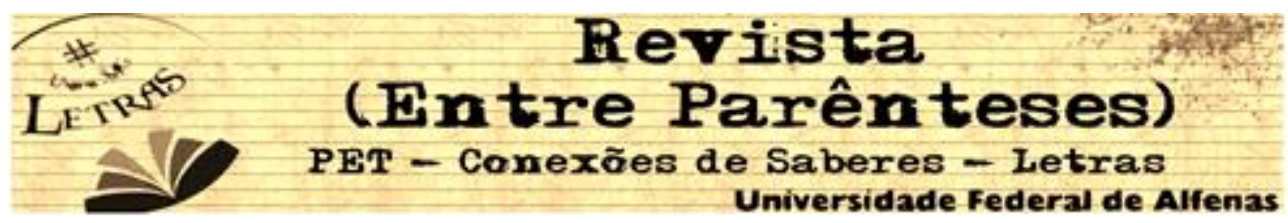

\title{
A FAUNA E A FAINA APONTAMENTOS PARA UMA LEITURA DE O CORTIÇO
}

\author{
Eloésio Paulo ${ }^{1}$ \\ Universidade Federal de Alfenas \\ (eloesio@gmail.com)
}

Resumo: Este artigo, dirigido sobretudo a professores e a futuros professores de Literatura Brasileira, pretende oferecer subsídios para uma compreensão crítica do romance $O$ cortiço, de Aluísio Azevedo. Para tanto, procura mobilizar elementos que permitam, ao leitor de primeira viagem dessa obra, reconhecer as qualidades de técnica narrativa que a tornaram um clássico da ficção brasileira, bem como apontar as situações narrativas mais relevantes para compreender a complexa rede de referências históricas e a intenção profundamente crítica do escritor, fundamentais para a sobrevivência do romance como leitura potencialmente prazerosa e monumento à inteligência brasileira, vale dizer, obra cuja frequentação é indispensável na formação de um cidadão capaz de aliar, em todas as situações de sua vida, sensibilidade e consciência social.

Palavras-chave: Ficção brasileira; Romance naturalista; Aluísio Azevedo; O cortiço.

Abstract: This article, mostly directed to Brazilian literature teachers and for those who intends to be, it wants to offer background to a critic comprehension of the novel $O$ cortiço, by Aluísio Azevedo. For this purpose, it pursues to mobilize elements that allow "rookie" readers of this book recognize the qualities of the narrative techniques that made it a classic into Brazilian fiction. It also intends to point out the most relevant narrative situations in order to make clear the intricate net of historical references and the deeply critic intention of the author, fundamental issues for the novel subsistence as potentially enjoyable reading and a landmark to Brazilian intelligence - in other words, a book to what the visitation is essential to the upbringing of citizens that are capable to combine, in all situations of their life, sensibility and social conscience.

Keywords: Brazilian Fiction; Naturalist Novel, Aluísio Azevedo; O cortiço.

Resumen: Este artículo, dirigido especialmente a profesores y futuros profesores de Literatura Brasileña, pretende ofrecer aportes para una comprensión crítica de la novela $O$ cortiço, de Aluísio Azevedo. Para tanto, busca movilizar elementos que permitan, al lector en su primer contacto con la obra, reconocer las calidades de la técnica narrativa que la hicieron un clásico de la ficción brasileña, además de puntuar las situaciones narrativas más relevantes para comprender la compleja red de referencias históricas presentes en la obra y la intención profundamente crítica del escritor, fundamentales para la supervivencia de la novela como una lectura potencialmente agradable y un monumento a la inteligencia brasileña, vale decir, obra

${ }^{1}$ Eloésio Paulo é professor da Universidade Federal de Alfenas. Doutor em Letras pela UNICAMP (2004), publicou os livros Teatro às escuras - uma introdução ao romance de Uilcon Pereira (1998), Os 10 pecados de Paulo Coelho (2007) e Loucura e ideologia e dois romances dos anos 1970 (2014). 


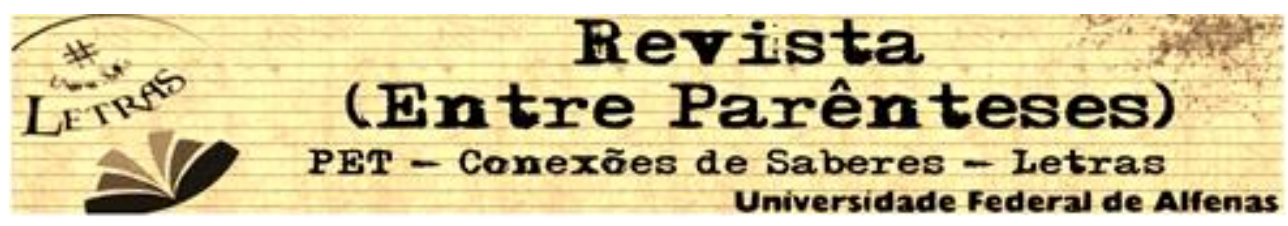

cuya lectura es indispensable en la formación de un ciudadano capaz de unir, en todas las situaciones de su vida, sensibilidad y conciencia social.

Palabras-clave: Ficción brasileña; Novela naturalista; Aluísio Azevedo; O cortiço.

O que primeiro salta aos olhos, na leitura de $O$ cortiço, é a incomum habilidade de seu autor para orquestrar os elementos essenciais da narrativa. Tal habilidade sofreu uma espécie de eclipse, na obra de boa parte dos escritores em atividade durante o século $X X$, como se a avalanche das vanguardas pudesse cancelar na totalidade o chamado pacto realista. De saída, na obra do ficcionista maranhense, o leitor depara com uma condução do relato que o leva, como nas melhores narrativas afeitas ao dito pacto entre 0 leitor e a ficção, "pendurado" pelo interesse de saber o que vem a seguir.

Aluísio é antes de tudo um narrador habilíssimo. Sua técnica, lastreada no talento de desenhista, foi desenvolvida por meio da elaboração de folhetins ao gosto romântico - para vender, pois o ex-futuro pintor precisava sobreviver no Rio de Janeiro - e na confecção de peças de teatro, algumas em parceria com seu irmão Artur Azevedo, já estabelecido na capital do Império como escritor de prestígio quando Aluísio chegou, vindo de São Luís, para tentar a sorte. O desenhista nordestino inicialmente virou caricaturista, exercitando na imprensa carioca a mordacidade que já o tornara notável (e detestado por muitos) na capital maranhense, onde ainda morava quando publicou em 1881 os 500 exemplares da primeira edição de $O$ mulato, livro que inaugura a ficção naturalista no Brasil.

Esse romance, um tanto influenciado pelo anticlericalismo de Eça de Queirós em $O$ crime do padre Amaro (1875), viera coroar a participação de Aluísio na polêmica entre os jovens intelectuais provincianos e os padres de São Luís. A publicação da obra foi assunto recorrente na imprensa do 


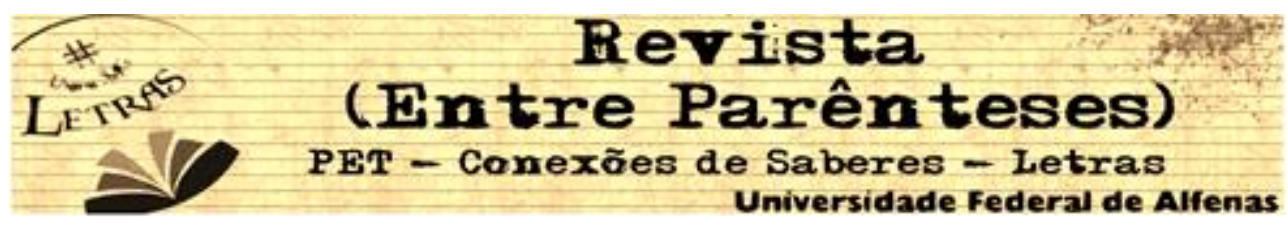

Maranhão, por meio da qual se digladiavam os proselitismos radicalmente antagônicos da carolice tradicional e do "bando de ideias novas", expressão de Silvio Romero para definir a visão cientificista então recém-chegada dos centros europeus da cultura, especialmente de Paris. Euclides Faria, sob o pseudônimo de Joaquim de Albuquerque, fustigou meses a fio a ousadia do rapaz que levava à ficção alguns conhecidos podres do clero de São Luís, ridicularizado a falsa beatice da província. Mas, além dos vitupérios maranhenses, o livro granjeou para o autor a saudação de Urbano Tavares: a intelectualidade do Império deveria atentar, como importante fato cultural, para o surgimento daquele "romancista ao Norte".

O livro de estreia do escritor tinha sido Uma lágrima de mulher (1879), cuja sensaboria torna espantoso que já o segundo volume da ficção aluisiana, mesmo sem lograr uma superação do Romantismo, tivesse qualidade tão superior. A capacidade de evolução rápida do escritor levara-o, na acertada expressão de Orna Messer Levin, ao "ponto de virada" não só da sua ficção, mas do próprio romance brasileiro, que passava a ter uma segunda finalidade a pregação de reformas sociais - além dos anteriores objetivos de educação moral e entretenimento, esperados pelos leitores e cumpridos satisfatoriamente por ficcionistas como Alencar e Macedo.

Com Casa de Pensão (1887), Aluísio deu um passo adiante e progrediu da observação dos costumes provincianos para a investigação metódica e já mais afim à técnica de Zola que à de Eça, de fenômenos característicos de um Rio de Janeiro em acelerada - para os padrões de nossa situação periférica - transformação das condições de sua vida urbana. Entre esses fenômenos se incluem as habitações coletivas, sendo a pensão de Madame Brizard e João Coqueiro um esboço daquele espaço muito maior e mais densamente povoado que seria figurado no cortiço. Existem evidências do 


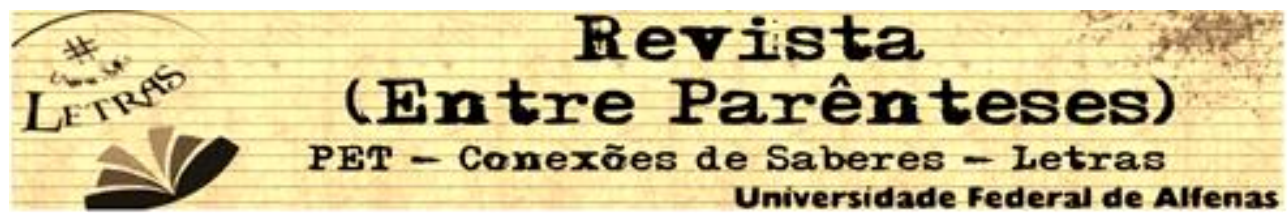

interesse de Aluísio por esse tipo de ambiente, um interesse de pesquisador disposto e habituado, segundo o depoimento de Pardal Mallet, ao travestir-se de trabalhador braçal para documentar a vida da população pobre do Rio. A observação da reciclagem de episódios e personagens pelo autor, de uma obra para outra, mostra que $O$ cortiço já vinha sendo gestado havia alguns anos, pois Aluísio publicara uma crônica sobre o ambiente das casas de cômodos (incluída no volume $O$ touro negro, de escritos dispersos) e também descrevera no folhetim $A$ condessa Vésper, cuja versão original saiu em 1882, uma estalagem de "centenas de portas" e caracterizada pelo "alegre rumor do trabalho".

O cortiço, publicado em 1890, costuma ser reconhecido como o ápice da produção de Aluísio. E com razão, pois as novas técnicas narrativas experimentadas em O homem (1887), O coruja (1890) e Livro de uma sogra (1895) podem ter aproximado o escritor de uma concepção mais moderna de ficção, contudo o distanciaram de seu natural talento, tão ligado à pintura e ao teatro como ao folhetim romântico do qual jamais logrou desvencilhar-se por completo. Nas palavras de Lúcia Miguel-Pereira, a linha de $O$ cortiço era mais afim ao temperamento do autor, propenso à "narrativa em largas pinceladas, mais atenta ao movimento, à ação, do que às figuras, estas apreciadas mais exteriormente, pela sua participação no quadro, antes social do que individualmente."

É fácil resumir o enredo. João Romão, um imigrante português, herda do antigo patrão uma tasca nas proximidades de Botafogo e, trabalhando como besta de carga, inicia um lento e penoso processo de acumulação de capital. Logo passa a receber a ajuda de Bertoleza, escrava de cujas economias se apossa sob o pretexto de comprar-Ihe uma carta de alforria. Com a obstinação da avareza e uma desonestidade metódica, começa a construir casinhas de 


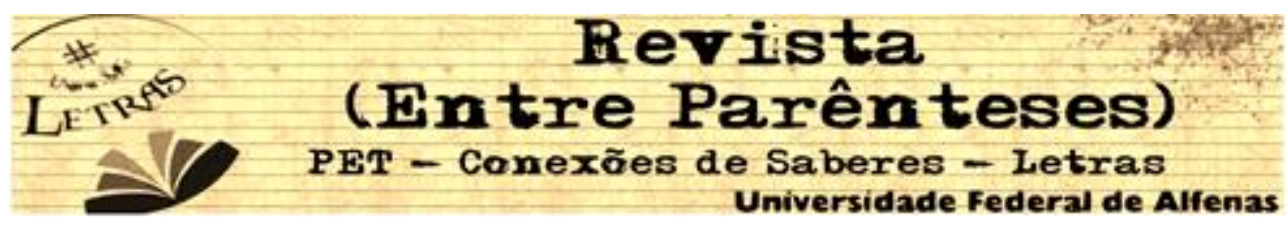

aluguel, logo chegando a ser dono de uma estalagem na qual passam a morar trabalhadores da mais modesta condição, entre os quais se contam, principalmente, lavadeiras de roupas. À medida que se multiplicam seus moradores, a própria habitação coletiva entra a ocupar o foco principal da narrativa, diluindo-se a história de João Romão e Bertoleza - inicialmente contraposta à do comerciante Miranda, que viera com sua família habitar um sobrado na vizinhança - num cortejo em que desfilam as dezenas de ocupantes da estalagem. O foco volta a concentrar-se naquele núcleo inicial por ocasião do estorvo que passa a representar, diante da intenção de um João Romão muito enriquecido de casar-se com uma "moça de família", a nódoa social do concubinato com Bertoleza.

A narrativa compreende, desde seu início, um invejável manejo do tempo. A paisagem do cortiço e de seus arredores, assim como as personagens, vão sendo caracterizadas com agilidade e concisão, evoluindo o relato diante dos olhos do leitor, quase como numa peça de teatro. Os parágrafos são curtos e os eventos, dispostos em rápida sucessão, com mudanças ao mesmo tempo bruscas e quase imperceptíveis de ângulo narrativo. Essa - por assim dizer - técnica de aquarelista não impede que o escritor tenha senso de detalhe, e assim a ambição capitalista de João Romão é dada ao leitor, em meio à conversa do vendeiro com Jerônimo, por um simples advérbio, quando o primeiro declara, diante da pedreira já incluída a seus domínios, que "Toda esta parte que se segue agora (...) ainda não é minha."

Demonstração semelhante são os comentários das vizinhas a respeito de Rita Baiana. A mulata ainda não compareceu às páginas do romance, mas ficamos sabendo que ela "tem fogo no rabo", anda amigada com um tal Firmo e demonstra-se pouco responsável como lavadeira, mesmo assim não sendo má 


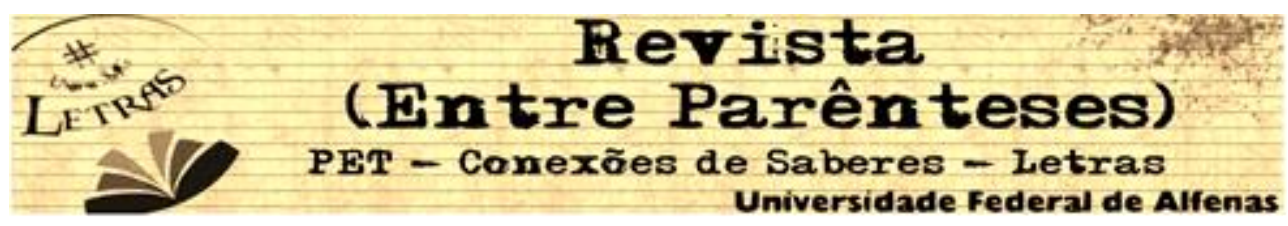

criatura. A mesma técnica apresenta Jerônimo e Piedade: quando os trastes do casal de portugueses começam a ser descarregados na frente da casinha que ocuparão, a conversa das vizinhas mostra que, além de ser um "pedaço de homem", o cavouqueiro ostenta uma posição social ligeiramente superior à média dos moradores do cortiço. Posição coerente com a capacidade anteriormente demonstrada por Jerônimo de arrancar um salário melhor do que se dispunha a pagar o dono da pedreira, já nessa altura em vias de ser qualificado pelo narrador como "ente atrofiado pela cobiça".

Enfim, por meio de diálogos as personagens são desenhadas e os episódios futuros são engatilhados. Por exemplo, não é nada ocasional o surgimento de Jerônimo no relato logo após a conversa das lavadeiras sobre o paradeiro de Rita Baiana; quando os dois se encontram, páginas adiante, a história de seus amores passa a ocupar boa parte da narrativa, constituindo um subnúcleo privilegiado no desenvolvimento do enredo.

No início do romance, também a descrição do ambiente é muito importante. Ela situa a "labutação" intensa a que se entregam as lavadeiras, os trabalhadores da pedreira e o próprio João Romão com sua Bertoleza, agora mais escrava do que antes. Tudo sob um sol de cuja intensidade os efeitos cromáticos sobre a paisagem são objeto de grande atenção do narrador. Mas este também está, além de preocupado em descrever a faina coletiva que resultará no vertiginoso sucesso de João Romão como ganhador de dinheiro, bastante empenhado em caracterizar os habitantes do cortiço como variada fauna cujas características pessoais e sociais são, de maneira bem adequada ao figurino do Naturalismo, traduzidas em expressões zoomórficas que nivelam homem e animal. Destacadamente, o másculo Jerônimo é com insistência comparado a um touro, caracterização depois transferida ao tratamento dispensado a Piedade, a qual, abandonada pelo marido, expressará o próprio 


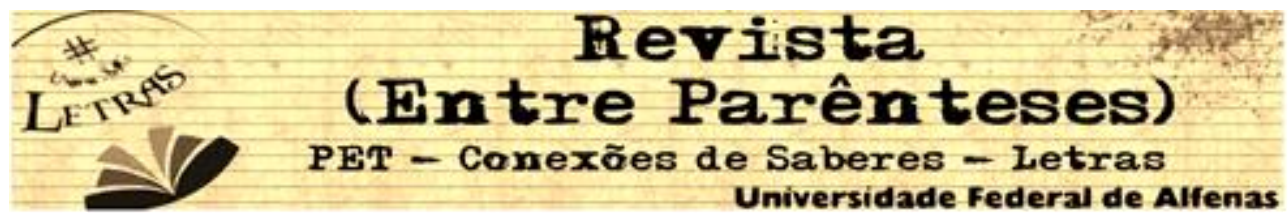

sofrimento por meio de "mugidos".

Mas, na engenhosa economia da narrativa, as descrições da estalagem vão-se tornando cada vez menos necessárias, pois o leitor em breve terá na mente um mapa do cortiço e de seus moradores. Nesse ponto o relato já chegou a sua metade e estão desenhados ou pelo menos esboçados os vários conflitos que comporão o romance da coletividade. A antipatia entre João Romão e Miranda, por exemplo, está em marcha desde a disputa em torno da construção de um muro separando as duas propriedades. O drama de Pombinha, que consiste no atraso da puberdade, também se desenrola à vista do leitor, assim como diversos conflitos menores que ao mesmo tempo distraem e compõem uma eficaz impressão de variedade humana. Na rápida passagem do próprio trabalho à feroz exploração do alheio, João Romão fizera surgir do nada uma numerosa comunidade várias vezes comparada, pelo narrador, à aglomeração de vermes ou insetos.

Apesar dessa imagem deprimente, também existe no cortiço espaço para o "prazer animal de existir". Ocorre que o exercício desse prazer, salvo engano, verifica-se nos momentos de ócio. É um tópico de estudo interessante sobre o romance, essa atenção do autor às delícias do far niente. Afinal, o grande problema existencial de Aluísio parece ter sido a falta das condições ideais para a criação artística, falta que inicialmente o obrigou a desistir da pintura e depois levou-o a redigir folhetins ao gosto do público menos exigente, afinal frustrando suas expectativas de, ingressando na carreira diplomática, dispor de tempo para escrever apenas as obras que de fato lhe interessavam. Muito se lamentou Aluísio de que suas posições diplomáticas nada tinham a ver com o sossego de vilegiatura desfrutado por Eça de Queirós em Bristol, Inglaterra.

Aquele "verminar constante de formigueiro assanhado" significa que a 


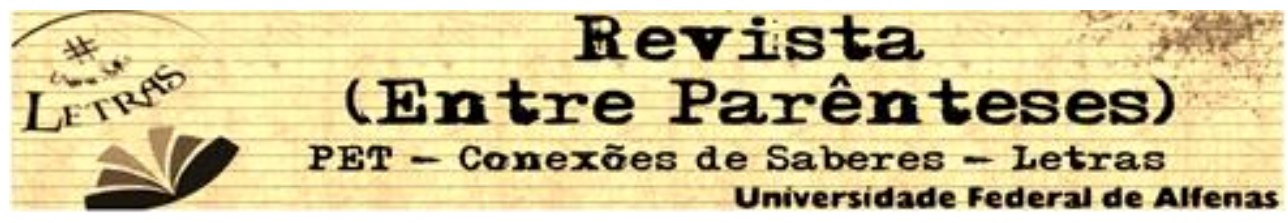

obsessão capitalista de João Romão atingira seu objetivo. Na multiplicação do número de braços explorados pelo vendeiro, a coletividade inicialmente descrita de maneira quase impressionista como "coisa viva" passa a ser designada como "feroz engrenagem" de uma "máquina terrível". Já agora a estalagem, paradoxalmente beneficiada por um fogo posto pela lavadeira apelidada de Bruxa, ganhava ares de ambiente respeitável, "lançando os dentes a uma nova camada social" enquanto expulsava para o antigo rival, o cortiço Cabeça-de-Gato, o lúmpen que pudera, em poucos anos, enriquecer João Romão a ponto de torná-lo pretendente viável à mão de Zulmira, a filha do Miranda. A compra do baronato por esse vizinho, que inicialmente enchera o vendeiro de desgosto, é um estímulo para que João Romão sonhe tornar-se nada menos que visconde, enquanto o cortiço se "aristocratiza".

Daí ao desfecho trágico é um pulo, porque novamente o dono do lugar, como se pudesse usurpar até mesmo os dramas da população que o enriquecera, está no centro da narrativa. Na maior parte da história, suas aparições tinham-se tornado uma espécie de baixo-contínuo marcando o concerto de existências, mas agora surge a questão de como livrar-se de Bertoleza, e o enredo volta a ter como protagonistas suas personagens inaugurais.

Lúcia Miguel-Pereira criticou o suicídio de Bertoleza como recurso barato e desnecessário à economia narrativa de $O$ cortiço. Talvez o livro, de fato, pudesse passar sem a tragédia, mas ele não seria, sem ela, o que se tornou: um romance naturalista cujo excesso de fidelidade ao ideário de Zola acaba atenuado pela sobrevivência de traços românticos em sua estruturação. É possível perguntar: se João Romão transigira a respeito do salário de Jerônimo e do achaque praticado pelo velho Botelho, por que não the seria mais fácil subornar regiamente a ex-concubina do que atraiçoá-la de modo tão 


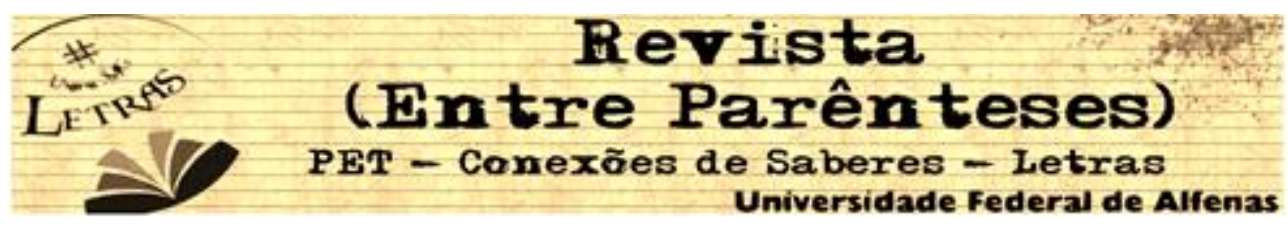

vil? Aqui parece que o impulso à tragédia fez a narrativa contornar o leito que Ihe seria, à primeira vista, mais verossímil: o do cálculo interesseiro conatural à mentalidade burguesa. $\mathrm{E}$ ninguém duvida de que o tosco taberneiro tenha conseguido tornar-se ao menos um tosco burguês, daqueles típicos do estádio capitalista que a ciência econômica chamou "acumulação primitiva".

Essa, no entanto, é uma pergunta sem solução, como seria indagar por que em nenhum momento surgiu, da parte da família do Miranda, a ideia de casar Zulmira com o estudante de medicina que Ihes vivia sob o teto. Ao contrário, as incursões amorosas de Henrique na casa restringem-se à acolhedora dona Estela, que por sinal daria, uma vez caindo em algum enredo machadiano, matéria-prima suficiente para outra Virgília ou Sofia.

O desfecho vem confirmar o incômodo romantismo ainda imbricado no Naturalismo de Aluísio. Mas o que seria de $O$ cortiço caso se tivesse tornado, conforme o plano inicial do autor, o primeiro volume de uma série de cinco, intitulada Brasileiros antigos e modernos? Provavelmente resultaria numa narrativa diluída, e, ao contrário, o fato de ter abortado essa ideia de imitar tão obviamente a obra cíclica de Zola, a saga dos Rougon-Macquart iniciada com Thérèse Raquin (1867), resultou precisamente em que $O$ cortiço concentra todas as dimensões da sociedade brasileira que o escritor maranhense pensara explorar por partes. Antonio Arnoni Prado, corretamente, considerou 0 principal mérito de Aluísio não ter copiado Zola e sim compreendido o "espírito da revolução" concebida pelo pai do Naturalismo, adaptando-o criativamente à análise das condições brasileiras.

Também está com a razão Antonio Candido quando, depois de notar (na esteira do que já havia feito Pardal Mallet) uma série de coincidências, até certo ponto embaraçosas, entre o romance de Aluísio e L'assommoir, de Zola, que desde o título parece ter informado a criação do brasileiro, relativiza a 


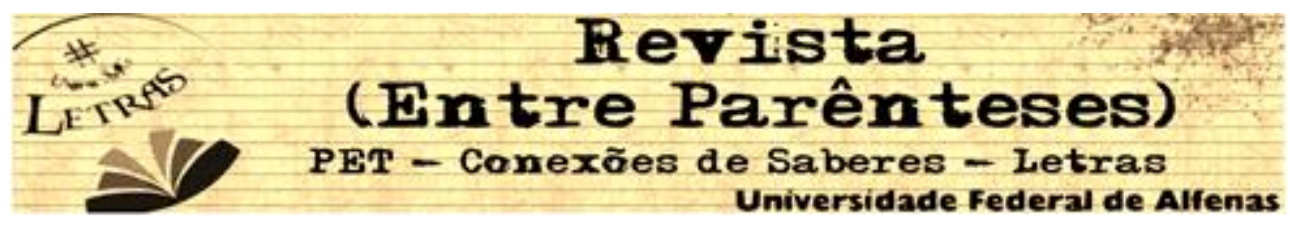

semelhança entre as obras e dela parte para uma análise que desemboca em juízo bastante favorável a $O$ cortiço. Para Candido, a estruturação da obraprima de Aluísio envolve a percepção da diferença entre os processos de exploração capitalista na França, centro do sistema, e na situação periférica do Brasil. Além disso, diz o crítico, trata-se do primeiro romance brasileiro a colocar em pauta a centralidade da acumulação do capital no processo histórico, indo muito além dos efeitos casuais da posse do dinheiro nos enredos de Machado de Assis e José de Alencar. Outro aspecto importante do romance notado por Candido é a passagem, do surgimento da estalagem até sua modernização posterior ao incêndio, de um funcionamento "orgânico" ao mecanicismo dirigido pelo jogo bruto da acumulação. Ainda nas palavras do crítico, uma interposição do Brasil real como mediador entre a figuração do cortiço e nossa percepção da pobreza acarreta, para o romance de Aluísio, uma perda quando se pensa no "alcance geral" do livro, mas em contrapartida "aumenta seu significado específico".

Essas qualidades não nos autorizam, obviamente, a fechar os olhos ao fato de que o romance tem defeitos diretamente relacionados ao mesmo compromisso entre Naturalismo e Romantismo que parece dialeticamente concorrer para seus grandes méritos como obra literária. A insistência no fato de Rita Baiana ser "volúvel como toda mestiça", por exemplo, é uma estereotipagem difícil de justificar, mesmo considerando o contexto em que o romance foi escrito. O mesmo se diga dos supostos "direitos de apuração" racial que levam a mulata a escolher o português em detrimento do Firmo, ao passo que Jerônimo, deixando-se abrasileirar - e isso inclui tornar-se alcoólatra e preguiçoso -, tê-lo-ia feito por "ceder às imposições mesológicas". Fica exposta em passagens como essas a subserviência do autor ao ideário naturalista, de resto correspondente ao espírito do texto teórico fundador do 


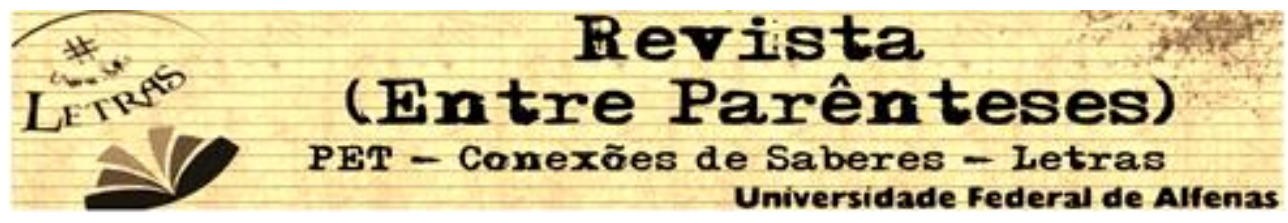

estilo, em que Zola subscreve na totalidade os estudos de "medicina experimental" Claude Bernard, subordinando a criação literária ao método científico.

Por isso mesmo é notável, a propósito da apaixonada relação entre 0 cavouqueiro português e a mulata, que em nenhum momento a narrativa se tenha aproximado da ousadia descritiva empregada por ocasião da quase sádica apropriação da esposa adúltera pelo Miranda, ou mesmo da impertinente violentação lésbica de Pombinha pela cocotte Léonie. No máximo, ao descrever a tórrida relação do português com a mulata, Aluísio vai ao embornal das metáforas românticas buscar "uma agonia de anjos violentados por diabos, entre a vermelhidão cruenta das labaredas do inferno."

$E$, por falar em linguagem, essa é uma dimensão do romance que merece muita atenção. Entre tais incursões líricas um pouco desajeitadas e a explicação grosseira de que Pombinha se encaminhava para sua primeira menstruação devidamente "lubrificada por essa recordação", ou seja, a de seu "estupro" sáfico, o romancista encontra momentos felizes sobretudo devido a sua evidente preocupação em documentar (como no demais referente à habitação coletiva) os registros populares da fala. Esses momentos estão entre as passagens mais saborosas do romance, e deles se destaca a discussão do ferreiro Bruno com sua mulher apanhada em flagrante delito de adultério. A cena é de uma comicidade que chega a lembrar passagens das Memórias de um sargento de milícias, obra à qual Aluísio parece ter ido recortar, para reciclá-lo, o famoso episódio da pisadela e do beliscão: o primeiro contato erótico de Jerônimo e Rita Baiana é bastante parecido com o de Leonardo Pataca e Maria da Hortaliça.

Note-se, ainda, que a palavra "bunda" deve ter aparecido pela primeira vez, em obra literária, na passagem em que uma mãe ameaça o filho de 


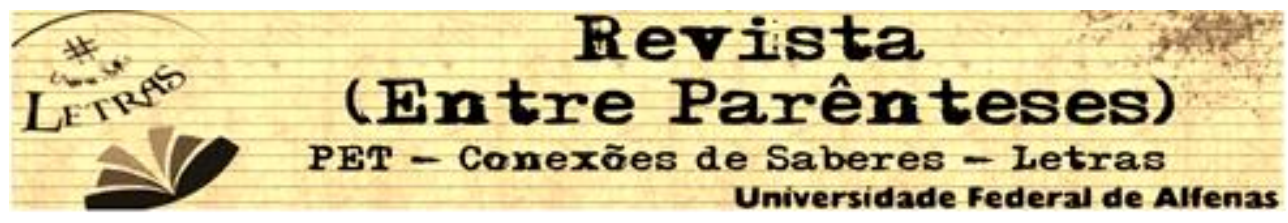

"encher-lhe" de chineladas a dita parte da anatomia. Também parece ser a primeira vez que um escritor brasileiro usa o neologismo "macarronear" para referir-se à fala dos italianos.

Do outro lado da balança ficam algumas repetições desnecessárias como a do adjetivo "estrompado", que faz supor certo descuido na escolha do vocabulário. E não foram resolvidos, até hoje, determinados empregos um tanto discutíveis da vírgula por Aluísio; se é verdade que parte deles pode resultar do que eram as convenções da pontuação na época, às vezes parece evidente que a opção, aparentemente feita pelo autor, decorreu na realidade de pouco cuidado dos responsáveis pelas primeiras edições do romance. Seria necessário um estudo estilístico minucioso para o definitivo estabelecimento da pontuação não só em $O$ cortiço, mas em toda a obra do escritor. De qualquer modo, registre-se que a virgulação de Aluísio não deve ser imitada por alguém que pretenda escrever de maneira adequada ao uso contemporâneo do português brasileiro.

Outros elementos estão a atestar que $O$ cortiço, embora obra-prima do autor e do Naturalismo brasileiro, está longe de enquadrar-se no ideal flaubertiano do mot juste e de rivalizar com Eça e Machado, tanto no que se refere ao estilo como no que tange à perfeição estrutural. Assim é que o usual recurso do Romantismo a soluções fáceis para o enredo aparece no romance na forma de uma visita excessivamente a propósito de Botelho a João Romão, exatamente no momento em que este procurava a solução para eliminar Bertoleza. Também as últimas páginas do livro contêm aquela espécie de resumo de destinos que costuma alinhavar às pressas não só muitas narrativas românticas, mas especialmente as telenovelas, as quais em muitos aspectos, como se sabe, corporificam a degeneração extrema do enredo folhetinesco.

Se não se trata de uma obra perfeita, por que então obra-prima? 


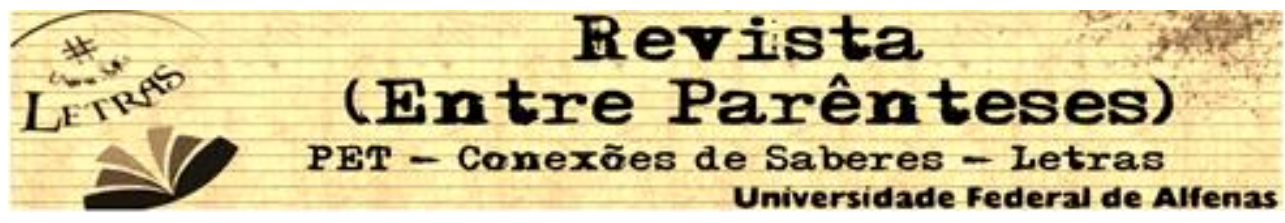

Qualquer livro tem suas contingências, podendo ser uma delas a própria busca da perfeição. Ora, por definição a obra ficcional aluisiana é marcada pela contingência de ter o escritor empreendendo o impossível: viver de literatura no Brasil, o que até hoje é privilégio de poucos, e nem sempre em razão de qualidades especificamente literárias. Além de produto do trabalho de um escritor nas condições culturais específicas do Brasil no final do século XIX, o romance é a tradução de um momento social ímpar, e nesse sentido continuará sempre sendo único. Não há melhor retrato da feroz acumulação primitiva que caracterizou aquele momento do capitalismo brasileiro, e que sabemos continuar sendo a marca do "desenvolvimento" econômico até mesmo em certos recantos do Sudeste e do Sul supostamente integrados à economia moderna.

Para ficar num exemplo de obra ficcional contemporânea em muitos aspectos semelhante a Cortiço - pois há várias, o que já depõe sobre o caráter paradigmático do livro de Aluísio -, o romance Cidade de Deus, de Paulo Lins, ganhou rápida e merecidamente seu lugar de clássico de nossa ficção em boa parte por esse parentesco. Sempre será necessário olhar para esses retratos impiedosos (ainda que eventualmente suavizados por certo romantismo) de nossa sociedade para não esquecermos o quanto ela segue sendo exatamente o que sempre foi: impiedosa.

\section{REFERÊNCIAS}

AZEVEDO, A. Ficção completa. Organização de Orna Messer Levin. Rio de Janeiro: Editora Nova Aguilar, 2005. 2 vols.

ALONSO, A. Ideias em movimento; a geração 1870 na crise do BrasilImpério. Rio de Janeiro: Paz e Terra, 2002.

CANDIDO, A. "De cortiço a cortiço". Em O discurso e a cidade. Rio de 


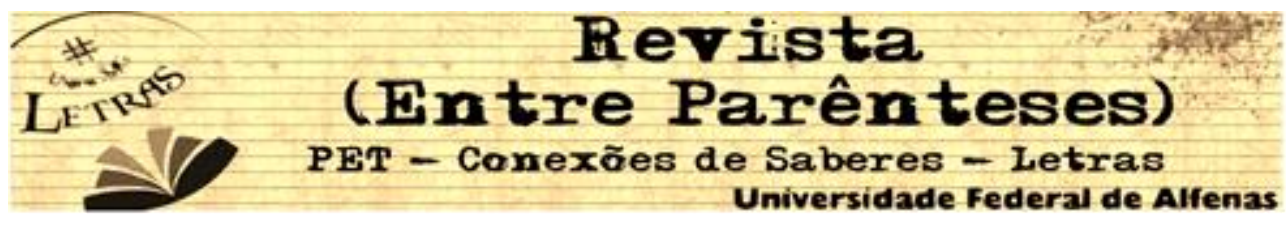

Janeiro: Duas Cidades/Ouro Sobre Azul, 2004, p. 105-132.

DIMAS, A. Aluísio Azevedo; Literatura comentada. São Paulo: Abril Educação, 1980.

FERREIRA, L.A. Roteiro de leitura: O Cortiço. São Paulo: Ática, 1997.

FURST, L.R. e SKRINE, P.N. O naturalismo. Lisboa: Lysia, 1975.

MÉRIAN, J.-Y. Aluísio Azevedo; vida e obra (1857-1913). Rio de Janeiro: Espaço e Tempo/INL, 1988.

MONTELLO, J. Aluísio Azevedo e a polêmica d'O mulato. Rio de Janeiro: Livraria José Olympio, 1975.

SALES, H. Para conhecer melhor Aluísio Azevedo. Rio de Janeiro: Bloch Editores, 1973.

SCHWARZ, R. "Adequação nacional e originalidade crítica". Em Sequências brasileiras. São Paulo: Companhia das Letras, 1999. p. 24-45.

WEBER, J. H. Caminhos do romance brasileiro. Porto Alegre: Mercado Aberto, 1990.

WEHRS, C. O Rio antigo de Aluísio Azevedo. Rio de Janeiro: Gráfica Editora do Livro, 1994

ZOLA, E. O romance experimental e o Naturalismo no teatro. São Paulo: Perspectiva, 1982.

Recebido em: 05/12/2016

Aceito em: 20/12/2016 